\title{
Menggali Kebijakan Penyiaran Digital di Indonesia
}

\author{
Nur Malik Maulana \\ Magister Ilmu Komunikasi, Universitas Diponegoro, \\ Jalan Erlangga Barat VII No. 33 Semarang 50241, Indonesia \\ Email: nurmalikmaulana@gmail.com* \\ *corresponding author
}

\begin{abstract}
Digitizing broadcasting is a necessity that brings a new era of broadcasting in Indonesia. Digital technology is the right solution in overcoming the frequency limitations in analog broadcasting, but until now Indonesia has not yet realized digital broadcasting because there is no legal umbrella governing it and Law No.32/2002 on Broadcasting does not yet contain these rules. This research aims to provide policy ideas and regulations on digital broadcasting that should be made by the government. This research method is a documentation or library study by looking at data derived from several regulations on digital broadcasting in Indonesia and several related articles. The results showed a process of mutual influence between the agent and the structure behind the making of broadcasting digitalization regulation which is illustrated by the attraction of very strong interests between the interests of the public, capital owners, and the government. The choice of the multiplexing model used for digital broadcasting has been a heated debate. Single multiplexing is the most appropriate model to use. The control of frequency by the government creates the public sphere (public sphere) which contains a balance between private and public interests. So that the ideals of broadcasting with a diversity of ownership and diversity of content can be realized. The contribution of this research is in the form of recommendations to digital parties so that the regulation of digital broadcasting must be based on a balance between private interests and the public interest. Keywords: digital broadcasting, political economy, structuration, multipleksing, public sphere
\end{abstract}

\begin{abstract}
Abstrak
Digitalisasi penyiaran merupakan sebuah keniscayaan yang membawa era baru penyiaran di Indonesia. Teknologi digital menjadi solusi tepat dalam mengatasi keterbatasan frekuensi pada penyiaran analog, tetapi sampai saat ini Indonesia belum merealisasikan penyiaran digital dikarenakan belum adanya payung hukum yang mengaturnya dan UU No.32/2002 tentang Penyiaran belum memuat aturan tersebut. Penelitian ini bertujuan untuk memberikan gagasan kebijakan dan regulasi penyiaran digital yang seharusnya dibuat oleh pemerintah. Metode penelitian ini adalah studi dokumentasi atau pustaka dengan melihat data-data yang berasal dari beberapa regulasi tentang penyiaran digital di Indonesia dan beberapa artikel terkait. Hasil penelitian menunjukkan adanya proses saling pengaruh antara agen dan struktur dibalik pembuatan regulasi digitalisasi penyiaran yang digambarkan dengan tarik menarik kepentingan yang sangat kuat antara kepentingan publik, pemilik modal dan pemerintah. Pemilihan model multipleksing yang digunakan untuk penyiaran digital menjadi sebuah perdebatan sengit. Single multipleksing merupakan model yang paling tepat digunakan. Penguasaan frekuensi oleh pemerintah menciptakan ranah publik (public sphere) yang berisi keseimbangan antara kepentingan privat dan publik. Sehingga cita-cita penyiaran dengan diversity of ownership dan diversity of content dapat terwujud. Kontribusi penelitian ini berupa rekomendasi kebijakan kepada pihak digital agar regulasi penyiaran digital harus didasari keseimbangan antara kepentingan privat dan kepentingan publik. Kata kunci: penyiaran digital, ekonomi politik, strukturasi, multipleksing, public sphere
\end{abstract}

\section{Pendahuluan}

Tiga belas tahun berlalu sudah semenjak terjadinya kesepakatan negara-negara yang tergabung dalam konferensi International Telecommunication Union (ITU), termasuk Indonesia di dalamnya, tentang pelaksanaan migrasi teknologi penyiaran dari analog ke digital. Indonesia sampai sekarang belum bisa merealisasikan digitalisasi penyiaran karena regulasi sebagai payung hukum yang mengatur belum jadi dan masih saja dibahas di DPR.

Kondisi global menunjukkan bahwa $85 \%$ wilayah dunia sudahmulaimengimplementasikan televisi digital. Semua negara telah menetapkan tahun migrasi dari siaran analog ke digital negaranegara maju di Eropa dan Amerika Serikat 
bahkan telah mematikan siaran analog (analog switch-offlASO) dan beralih ke siaran digital. Di kawasan Asia, Jepang melakukan ASO pada Juli 2011, Korea pada Desember 2012, China pada tahun 2012, Brunei pada Juni 2014, Malaysia pada Desember 2015, Singapura, Thailand dan Filipina pada tahun 2015, sementara Vietnam pada tahun 2020 (Prabowo dan Arofah, 2017: 256).

Konferensi ITU di Jenewa tahun 2006 menyepakati bahwa masa transisi dari penyiaran analog ke digital, yang dimulai pada 0001 UTC 17 Juni 2006, harus berakhir pada tanggal 17 Juni tahun 2015 atau yang disebut The Millenium Development Goal. Beberapa negara berkembang diberi tambahan waktu lima tahun untuk proses transisi ini, atau tepatnya pada tahun 2020. Kemkominfo pada tahun 2011 pernah membuat rancangan bahwa pelaksanaan migrasi teknologi penyiaran dari analog ke digital di Indonesia harus melewati tiga fase yang total kesemua fase tersebut membutuhkan waktu 7 tahun. Indonesia menargetkan tahun 2018 menjadifase Total Analog Switch-Off dengan bermigrasi total ke penyiaran digital (Adnjani dan Mubarok, 2018). Sebagai contoh regulasi tentang digitalisasi penyiaran berhasil dibuat dan disahkan tahun ini, mengikuti perhitungan teknis yang pernah dibuat Kemkominfo tahun 2011, maka Indonesia baru akan menjalankan penyiaran digital pada tahun 2025. Ini sudah melewati target yang telah dibuat dan juga melewati batas waktu dari ketetapan Konferensi ITU.

Regulasi mengenai penyiaran digital, terutama televisi merupakan regulasi yang sangat vital. Meskipun kini dengan perkembangan teknologi informasi dan komunikasi yang pesat, new media menjamur dimana-mana. Ternyata di Indonesia penetrasi media masih dikuasai oleh televisi. Survei Nielsenkwartal III tahun2017 menunjukkan bahwa 96\% (52 juta) rakyat Indonesia masih menggunakan televisi sebagai media utamanya. Televisi masih menjadi media yang sangat seksi, dengan jumlah penonton terbanyak. Bagi masyarakat atau penonton, tentu televisi digital diharapkan menjadi perwujudan dari pusat ragam informasi dan hiburan

Perkembangan penyiaran televisi di Indonesia dimulai saat diterbitkannya UU No. 32/2002 tentang Penyiaran. Semenjak itu, banyak bermunculan televisi-televisi lokal di berbagai daerah di tanah air. Akan tetapi, terbatasnya alokasi kanal frekuensi analog pada tiap wilayah siar menjadi kendala. Teknologi digital yang membutuhkan bandwidth tiap saluran televisi lebih kecil sangatlah tepat mengatasi terbatasnya jumlah alokasi kanal frekeuensi pada penyiaran analog. Melihat minat masyarakat berpartisipasi begitu kuat, maka alternatif penerapan siaran televisi digital di Indonesia merupakan sebuah solusi untuk keterbatasan kanal frekuensi tersebut. Dengan sistem digital, beberapa Lembaga Penyiaran dapat bergabung dalam penyiarannya dengan satu kanal frekuensi digital (Djamal dan Fachuddin, 2011:322). Bahkan secara perhitungan matematis, kalau digunakan secara optimal bisa terdapat 72 saluran televisi digital dalam satu wilayah siar (Prabowo 2012: 309). Teknologi inilah yang membuka lebar-lebar pintu cita-cita penyiaran Indonesia yaitu terciptanyapenyiaran dengan diversity of ownership dan diversity of content.

Dilihat dari segi ekonomi, melimpahnya frekuensi pada sistem penyiaran digital ini merupakan sebuah lahan bisnis yang sangat menggiurkan. Bagi para pemain baru, ini akan menjadi peluang emas untuk merintis kekuatan baru di bidang penyiaran. Bagi para pemain lama, frekuensi ini dapat dimanfaatkan untuk pelebaran sayap bisnis penyiaran mereka sebagai bentuk dari spasialisasi, sehingga tetap bisa mendominasi pasar. Bahkan kalau dilihat dari motiv politik, frekuensi yang digunakan untuk penyiaran merupakan media untuk menghegemoni ideologi-ideologinya. Melihat hal tersebut diperlukannya sebuah regulasi, berbentuk Undang-Undang yang dilengkapi dengan peraturan pemerintah dan keputusan pemerintah terkait yang mengatur lebih secara teknisnya. 
Undang-Undang (UU) Penyiaran menjadi regulasi yang sangat krusial karena media penyiaran merupakan media komunikasi massa yang menggunakan frekuensi publik, dan mampu mempengaruhi masyarakat. Asumsi rasional yang digunakan untuk membuat kebijakan penyiaran dilandasi dari the scarcity theory yang menyatakan bahwa frekuensi radio yang digunakan sebagai media dalam penyiaran sejatinya terbatas jumlahnya (Eadie, 2009:97), namun tidak semua individu dapat menggunakannya. Pada dasarnya publik memiliki hak yang sama untuk memanfaatkannya. Perlu adanya pengaturan pengelolaan terkait penggunaan frekuensi tersebut. Konsep Habermass tentang ruang publik, yaitu ruang gagasan yang memberikan otonomi dan arena terbuka bagi perdebatan publik juga menjadi landasan fundamental sebuah kebijakan penyiaran. Akses terhadap ruang tersebut bebas dan ada jaminan kebebasan publik untuk menyalurkan ekspresi mereka. Media seharusnya merupakan ruang yang mampu menampung banyak suara dan menyajikan keseimbangan informasi (McQuail, 2010:179). Pada akhirnya tertuang pada Pasal 1 ayat 8 UU No.32/2002 tentang Penyiaran juga menyatakan spektrum frekuensi radio adalah gelombang elektromagnetik yang dipergunakan untuk penyiaran dan merambat di udara serta ruang angkasa tanpa sarana penghantarbuatan, merupakan ranah publik dan sumber daya alam terbatas.

Memang bisa dipahami bahwa pembuatan regulasi mengenai penyiaran digital ini tidaklah mudah. Ada beberapa persoalan yang melatarbelakangi baik kendala teknis maupun nonteknis. Sampai saat ini regulasi tersebut masih dalam tahap pembahasan di DPR dan masih belum menemui titik temu. Fokus utama perdebatan dalam digitalisasi penyiaran adalah model atau teknis pelaksanaan multipleksing apakah yang akan di pakai pada penyiaran digital. Puncak pertanyaannya adalah apakah penyelenggaraan multipleksing dipasrahkan sepenuhnya oleh negara atau pemerintah, berarti menggunakan model single multipleksing. Atau kah dengan menggunakan model hybrid multipleksing, yaitu Lembaga Penyiaran Swasta (LPS) juga diijinkan untuk menjadi Lembaga Penyelengara Multipleksing (LPPM) bersama-sama dengan pemerintah.

Belum banyak penelitian yang mengangkat tema penyiaran digital atau digitalisasi penyiaran di Indonesia. Prabowo (2012) memandang secara kritis Permen Kominfo yang mengatur perihal digitalisasi penyiaran dengan berpihak kepada eksistensi TV lokal yang dapat terancam. Budiman (2015) memaparkan secara deskriptif tentang penyiaran digital dan regulasinya secara normative dan tidak terlalu masuk ke area teknis. Penelitian lain lebih memberikan pandangannya tentang bagaimana sosialisasi migrasi penyiaran dari analog ke digital yang efektif (Prabowo dan Arofah, 2017; Mubarok dan Adnjani, 2018). Penelitian ini melihat lebih dalam perkembangan penyiaran digital di Indonesia menggunakan ekonomi politik kritis sebagai sudut pandangnya.

Berdasarkan paparan di atas, penelitian ini mencoba masuk ke dalam diskursus mengenai digitalisasi penyiaran di Indonesia dengan tujuan memberikan gagasan kebijakan dan regulasi penyiaran digital seperti apakah yang seharusnya dibuat oleh pemerintah.

\section{Metode Penelitian}

Jenis penelitian ini adalah deskriptif dan eksplanatif dengan mengkaji secara kualitiatif permasalahan menggunakan paradigma kritis dan pandangan ekonomi politik komunikasi. Objek yang diteliti adalah kebijakan maupun regulasi mengenai penyiaran digital di Indonesia. Kajian dilakukan secara studi dokumentasi atau pustaka. Data-data didapatkan dari kajian pustaka (literature review) berupa regulasi penyiaran digital di Indonesia dan beberapa artikel terkait. Setelah itu data-data tersebut dianalisis menggunakan teori ekonomi politik, sehingga memperoleh hasil simpulan berupa gagasan kebijakan dan regulasi penyiaran digital yang seharusnya dibuat oleh pemerintah. 


\section{Hasil Penelitian dan Pembahasan Ekonomi Politik Komunikasi}

Penelitian ekonomi politik telah menorehkan catatan sejarah pada perkembangan penelitian komunikasi, terutama tentang pandangan secara oposisi terhadap kekuatan dominan yang ada pada industri bidang komunikasi dan hubungannya dengan pemerintahan dalam hal ini para politisi (Mosco, 2009:109-113). Pendekatan ekonomi politik sekarang sering digunakan untuk mengkaji keberadaan media massa dalam masyarakat dan dianggap mempunyai signifikansi kritis berkaitan dengan kepemilikan dan kontrol media yang mengaitkan industri media dengan industri lain, elit politik, ekonomi dan lingkungan sosial. Wasko (2004) mengambil pandangan kritis Mosco dan Golding-Murdock, bahwa ekonomi politik dilakukan secara holistik, berkelanjutan dan berpusat pada interplay kepentingan antara kapitalis dan publik. Kajian ekonomi politik kritis mencakup tentang kepemilikan dan penguasaan, relasi kuasa, sistem kelas sosial dan ketidakadilan struktural, strategi untuk tetap berkuasa dan mempengaruhi (Wasko, 2004:311-314).

Dalam praksis, media telah bertransformasi menjadi produsen informasi. Informasi tak ubahnya barang komoditas yang diproduksi perusahaan para kapitalis yang tentunya mengedepankan keuntungan perusahaan. Di sisi lain, media massa merupakan sebuah kekuatan besar yang dapat memberikan pengaruh yang kuat. Dalam beberapa analisis tentang kehidupan sosial, ekonomi dan politik, media sering ditempatkan sebagai salah satu variabel yang determinan. Anthony Giddens dan Margareth S. Archer mendiskripsikan adanya saling pengaruh antara struktur dan agen. Bahwa proses dinamis untuk mengkonstruksi norma atau aturan ditentukan oleh tarik menarik dan saling pengaruh antara struktur (berupa sistem, aturan, kelas sosial) dan agen (aktor pelaku). Proses ini oleh Giddens disebut dengan "strukturasi". Besar kemungkinan proses inilah yang terjadi di balik lambatnya pembuatan regulasi penyiaran digital. Ada proses tarik menarik kepentingan yang sangat kuat antara kepentingan publik, pemilik modal dan pemerintah.

Konsep strukturasi yang ada di dalam pendekatan ekonomi politik menjadi salah satu pendekatan yang bisa digunakan sebagai cara pandang dalam tulisan ini. Ekonomi politik sebagai sebuah teori, menempatkan media sebagai bagian yang tidak terpisah dalam proses ekonomi, politik dan sosial masyarakat.

\section{Aliansi Konglomerasi: Agen Terkuat}

Carut marutnya regulasi penyiaran digital di Indonesia tak luput dari peran agen-agen yang terlibat di dalamnya. Pada tahun 2002, keluarnya UU No.22/2002 tentang Penyiaran berhasil mendorong demokratisasi informasi sekaligus membuka pasar media yang luas. Terbukanya pasar media mengakibatkan banyak berdirinya perusahaan-perusahaan media (privatisasi media). Namun, kebebasan media juga memunculkan masalah yaitu terjadinya pemusatan kepemilikan perusahaan media yang mengarah pada praktik konglomerasi. Pada dasarnya praktik konglomerasi media adalah ketika perusahaan media saling bergabung menjadi perusahaan yang lebih besar yang membawahi banyak media termasuk jenisjenis media yang beragam sebagai bagian dari bisnisnya. Hal ini bisa dilakukan dengan cara membeli saham, joint venture atau merger, atau akuisisi (mengambil alih). Saat ini terjadi tumpang tindih kehidupan media massa dalam hal kepemilikan. Di Indonesia, sebanyak 8 kelompok media besar menguasai saluran mulai dari media cetak koran, majalah, radio, televisi, serta jaringan berita onlinedari ujung Aceh hingga Papua. Diantaranya Visi Media Asia, MNC Group, Kelompok Kompas Gramedia, Elang Mahkota Teknologi, Grup Jawa Pos, CT Group, BeritaSatu media Holdings, Media Group.

Dari 8 konglomerasi tersebut, 5 diantaranya tergabung menjadi sebuah aliansi dalam Asosiasi Televisi Swasta Indonesia (ATVSI) yaitu Visi Media Asia dengan ANTV dan TvOne; MNC 
Group dengan RCTI, MNCTV dan GTV; Elang Mahkota Teknologi dengan SCTV dan Indosiar; CT Group dengan TransTV dan Trans7; dan Media Group dengan MetroTV. Stasiun televisi yang tergabung tersebut juga merupakan stasiun televisi dengan jangkauan penyiaran televisi secara teresterial terluas di Indonesia. RCTI memiliki 54 stasiun transmisi, TransTv memiliki 48 stasiun transmisi, SCTV memiliki 47 stasiun transmisi, Trans7 memilik 40 stasiun transmisi, Indosiar dan ANTV memiliki 33 stasiun transmisi. Ini menunjukkan bahwa ATVSI merupakan sebuah aliansi bisnis bernilai ekonomi yang sangat besar dan dengan pengaruh yang tidak kecil terhadap stabilitas ekonomi negara. Tentunya, segala regulasi yang berhubungan dengan area bisnis yang ditempatinya, yaitu penyiaran, salah satunya membutuhkan pertimbangan berupa masukan dari ATVSI. Ini menunjukkan bahwa ATVSI juga memiliki pengaruh politik yang kuat terhadap pembuatan sebuah norma atau aturan. Mosco (2009) dengan pandangan ekonomi politik kritisnya memberi perhatian bahwa kekuatan aliansi konglomerasi bisa mempengaruhi regulasi pemerintah (Mosco, 2009:165). Tentunya, pengaruh ini ditujukan dalam rangka usahanya (para kapital) untuk tetap bertahan dan menguasai. (lihat pengertian luas ekonomi politik menurut Mosco, 2009:25) Instrumentalisme: Pengaruh Agen Lebih Kuat

Berbicara mengenai regulasi digitalisasi penyiaran, pada tahun 2011 pemerintah melalui Kemkominfo mengeluarkan Peraturan Menteri (Permen) Kominfo No. 22/2011 tentang Penyelenggaraan Digitalisasi Penyiaran, disusul Permen No.23/2011 tentang Master
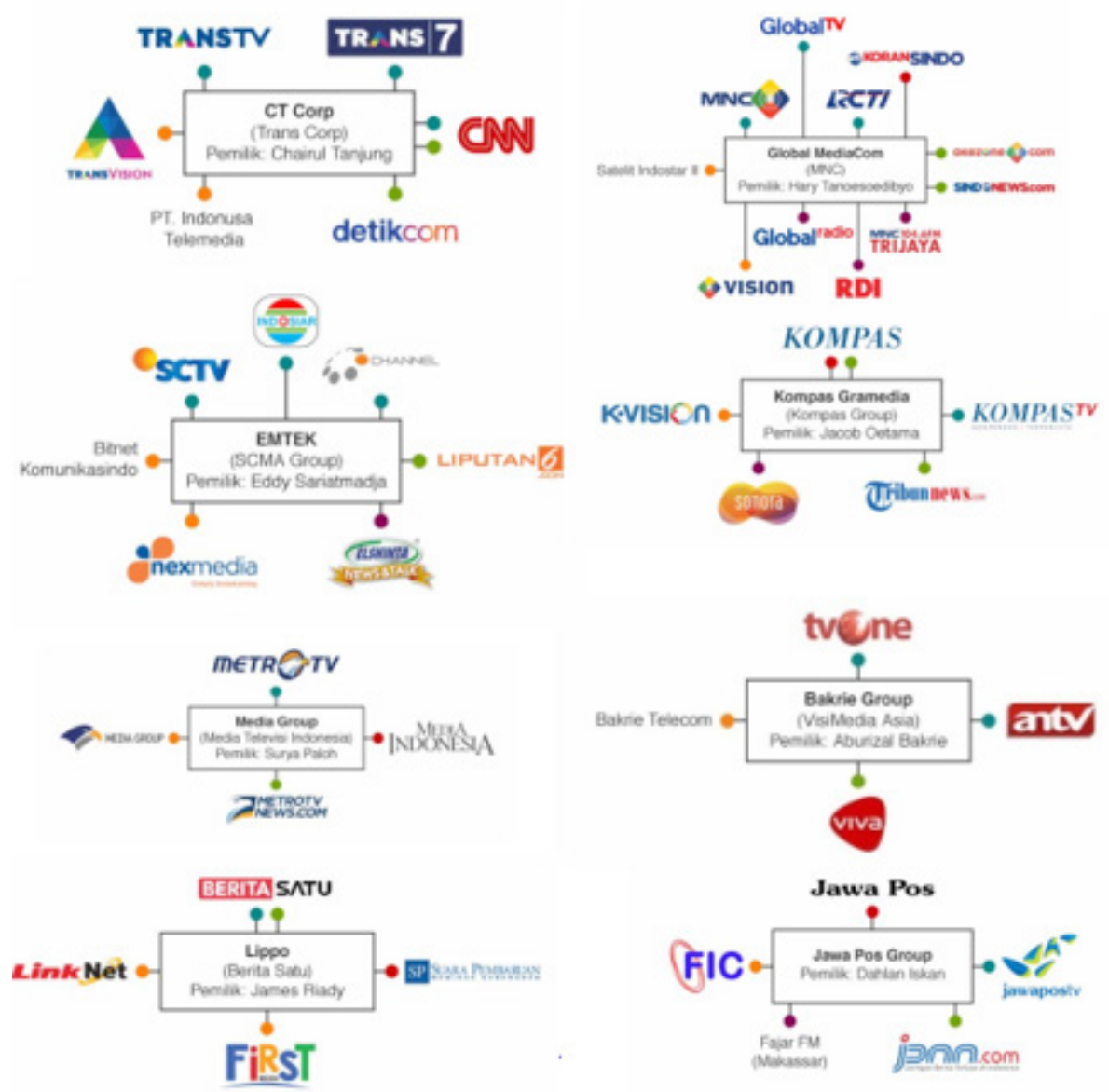

Gambar 1. Konglomerasi Media di Indonesia

Sumber: Tapsell, Ross dalam Sitepu, (2018) 
Plan Digitalisasi Penyiaran. Permen ini mengatur perihal teknis migrasi penyiaran dari analog ke digital dan model multipleksing yang digunakan dalam Permen No. 22/2011 ini adalah hybrid multipeksing, dimana Lembaga Penyiaran Publik (LPP) dan Lembaga Penyiaran Swasta (LPS) yang memiliki kemampuan teknologi yang mumpuni, ditunjuk menjadi operator atau Lembaga Penyiaran Penyelenggara Multipleksing (LPPM). Masingmasing operator multipleksing mengelola frekuensi dan infrastruktur penyiaran untuk dipergunakan oleh LPPatau LPS penyelenggara multipleksing itu sendiri dan LPS lainnya, melalui penyewaan kanal frekeunsi dan infrastruktur. Jumlah kanal frekuensi yang ditentukan adalah 6 kanal pada masingmasing wilayah siar, kecuali wilayah propinsi Kepulauan Riau hanya terdapat 4 kanal (lihat lampiran Permen No.23/2011). Jumlah kanal frekuensi tersebut akan dibagi pemakaian dan pengelolaannya kepada LPP TVRI dan LPS.

Keputusan Kemkominfo menggunakan hybrid multipleksing yang memberi ruang bagi LPS untuk menyelenggarakan multipleksing memunculkan keresahan di sebagian besar LPS lain. Dengan jumlah 6 kanal frekuensi yang ditetapkan, berarti hanya ada 5 LPS untuk 5 kanal frekensi yang ditunjuk sebagai LPPM karena 1 kanal sisanya sudah menjadi hak TVRI sebagai LPP. Kelima LPS yang tertunjuk nantinya, tentu akan memiliki kuasa terhadap 12 saluran program televisi atau LPS lainnya yang tergabung dalam kanal frekuensi tersebut (1 kanal bisa diisi maksimal 12 saluran televisi). Dan tentunya sangat dimungkinkan akan muncul norma-norma baru dari LPS yang tertunjuk sebagai LPPM dengan motif ekonomi politik yang sangat kental.

Belum mereda keresahan yang terjadi, pada Februari 2012, Kominfo mengeluarkan Kepmen Kominfo No. 95/2012 tentang Peluang Usaha Lembaga Penyiaran Swasta (LPS) sebagai Lembaga PenyiaranPenyelenggara Multipleksing
(LPPM) menjadi landasan hukum pemerintah saat itu untuk melakukan seleksi terbuka kepada LPS untuk menjadi pengelola penyelenggaraan penyiaran digital dengan multipleksing. Seleksi terhadap 5 zona siar (DKI dan Banten; Jawa Barat, Jawa Tengah dan DIY, Jawa Timur, Kepulauan Ritau) telah selesai dan diumumkan hasilnya melalui Siaran Pers No.65/PIH/ KOMINFO/7/2012 disusul dengan Siaran Pers No. 34/PIH/KOMINFO/4/2013 pada April 2013 untuk 2 zona, yaitu Aceh dan Sumatera Utara; dan Kalimantan Timur dan Kalimantan Selatan. Total 7 dari 15 zona layanan wilyah siar telah dilakukan seleksi dan hasilnya bisa dilihat dalam tabel 1 .

Tabel 1 menunjukkan bahwa LPS penyelenggara multipleksing terseleksi didominasi anggota ATVSI yang saat ini menguasai pertelevisian Indonesia, yaitu RCTI, MNCTV, GTV, TransTV, Trans7, MetroTV, ANTV, TvOne, SCTV dan Indosiar. Hanya ada satu LPS lokal, yaitu BSTV (BantenTV) yang ikut terpilih untuk zona DKI Jakarta dan Banten

Dominasi kanal frekuensi oleh ATVSI menjadi potensi terjadinya konflik. Penguasaan kanal frekuensi dan penyelenggaraan penyiaran digital oleh LPS akan memunculkan normanorma baru. LPS terseleksi akan berhitung secara ekonomis, untung rugi, terkait penguasaan kanal frekuensi tersebut. LPS atau televisi lain harus menyewa kanal frekuensi kepada LPS hasil seleksi. Dengan penguasaan atas sebuah frekuensi, LPS terseleksi yang menjadi LPPM dapat membuat aturan-aturan bisnis yang tentunya bertujuan akhir untuk keuntungan mereka dan akhirnya bisa menimbulkan potensi gugurnya satu per satu LPS-LPS lokal dengan kemampuan ekonomi yang relatif masih lemah. Hal ini bisa diartikan sebagai pemberangusan LPS atau televisi lokal (lihat Prabowo, 2012). Temuan Ashrianto (2015) juga menunjukkan bahwa di kota Jogjakarta, LPS atau televisi lokal bahkan belum siap secara teknologi, sumber daya manusia dan menejemen untuk melaksanakan penyiaran secara digital (lihat Ashrianto, 2015). 
Tabel 1. Hasil Seleksi LPPM

\begin{tabular}{llll}
\hline \multicolumn{1}{c}{ Zona Layanan } & Lembaga Penyiaran & \multicolumn{1}{c}{ Zona Layanan } & \multicolumn{1}{c}{ Lembaga Penyiaran } \\
\hline Zona Layanan 1 & RCTI Network & Zona Layanan 6 & Global TV \\
(Aceh dan Sumatera & ANTV Medan & (Jawa Tengah dan DIY) & $\begin{array}{l}\text { Indosiar Semarang } \\
\text { Utara) }\end{array}$ \\
& Trans7 Medan & & TVOne Semarang \\
& Metro TV Aceh & & Metro TV Jawa Tengah \\
& Indosiar Medan & & Trans TV Semarang \\
Zona Layanan 4 & BSTV & Zona Layanan 7 & ANTV \\
(DKI Jakarta dan & TVOne & (Jawa Timur) & Global TV \\
Banten) & Metro TV & & Metro TV \\
& SCTV & & SCTV \\
Trans TV & & Trans TV \\
(Jawa Bayanan 5 & ANTV Bandung & Zona Layanan 14 & Trans7 Samarinda \\
& Indosiar Bandung & (Kalimantan Timur dan & Global TV \\
& Metro TV Jabar & Kalimantan Selatan) & TVOne Samarinda \\
& RCTI Network & & Metro TV Kalsel \\
Trans TV Bandung & & SCTV Banjarmasin \\
(Kepulauan Riau) & RCTI Network & & \\
& SCTV Batam & & \\
\hline
\end{tabular}

Sumber: Siaran Pers No.65/PIH/KOMINFO/7/2012 dan Siaran Pers No. 34/PIH/KOMINFO/4/2013

Kemampuan LPS atau televisi lokal yang sangat terbatas harusnya menjadi perhatian pemerintah, sehingga kebijakan yang diterbitkan tidak hanya berpihak pada pemodal besar.

Regulasi yang tercipta berupa beberapa Permen Kominfo tersebut merupakan bentuk dari norma. Dalam pandangan ekonomi politik, norma terbentuk dari proses sosial dengan adanya saling pengaruh antara agen dan struktur. Keputusan pemerintah melalui Kemkominfo dalam menentukan LPS yang terseleksi sebagai LPPM jelas sangat berat sebelah dan memihak salah satu kepentingan relasi kuasa, yaitu ATVSI. Dalam pandangan ekonomi politik, ATVSI merupakan agen yang memberikan pengaruh yang lebih besar daripada struktur (pemerintah) dalam pembuatan norma (regulasi penyiaran digital). Tentunya pengaruh itu diberikan dengan tujuan agar ATVSI tetap bertahan dan menguasai penyiaran televisi di Indonesia. Pandangan ekonomi politik kritis menyebut varian ini sebagai instrumentalisme, yang cenderung menempatkan agen (tindakan yang secara nyata dilakukan oleh aktor sosial atau agen) pada posisilebih dominan dalam suatu strukturkultur. Media dipandang sebagai instrumen dominasi yang bisa dipergunakan sepenuhnya untuk kepentingan pengusaha atau pemilik modal. Multi atau Hybrid Multipleksing vs Single Multipleksing

Permen Kominfo yang mengatur tentang digitalisasi penyiaran tersebut mendapatkan pertentangan dengan alasan peraturan yang mengatur tentang digitalisasi penyiaran seharusnya setingkat Undang-Undang (UU), bukan Permen.UU Penyiaran baru untuk menggantikan UU Penyiaran No 32/2002 yang di dalamnya akan memuat regulasi digitalisasi penyiaran belum jadi dan bahkan belum selesai dibahas di DPR. Hal ini mengakibatkan semua Permen Kominfo yang mengatur tentang digitalisasi penyiaran diajukan untuk judicial review oleh sejumlah elemen masyarakat dan akhirnya Mahkamah Agung mengabulkan pada 13 April 2013. Pelaksanaan digitalisasi penyiaran di Indonesia pun menunggu selesainya UU Penyiaran yang baru. 
Setelah dibekukannya semua Permen Kominfo yang mengatur digitalisasi penyiaran, kebijakan mengenai masa depan penyiaran digital Indonesia ada di pundak DPR. Perjalanan pembahasan Revisi UU Penyiaran di DPR juga tidak kalah alotnya. Ada beberapa draft Rancangan Undang-Undang (RUU) yang pernah dibahas, yaitu RUU tertanggal Februari 2016, RUU tertanggal Meret 2017 dan yang terakhir RUU tertanggal Oktober 2017. Tiap RUU itu berisi regulasi yang berbeda secara fundamental terkait model penyiaran digital (sistem multipleksing) yang akan digunakan.

Di kalangan pelaku usaha penyiaran televisi yang oleh DPR dijadikan bahan pendapat penyusunan RUU, juga terjadi perbedaan yang mendasar mengenai model penyiaran digital apa yang akan digunakan nantinya. Seperti yang terjadi pada Diskusi PublikPengelolaan Penyiaran Digital dalam Revisi UU Penyiaran pada Rabu, 15 September 2017 yang diselenggarakan oleh Magister Ilmu Komunikasi FISIP Undip, menampilkan dua kubu yaitu kubu ATVSI yang menginginkan model hybrid sebagai model multipleksing penyiaran digital dan kubu Asosiasi Televisi Nasional Indonesia (ATVNI) bersama Asosiasi Televisi Lokal Indonesia (ATVLI) yang menginginkan model single sebagai model multipleksing penyiaran digital. Hal ini juga menambah alot dan lama perjalanan waktu revisi UU Penyiaran yang baru.

Di dalam pembuatan regulasi digitalisasi penyiaran, ATVSI; ATVNI dan ATVLI menjadi agen-agen yang memberikan pengaruh yang sama kuat dengan pendapat yang berbedakepada struktur (negara atau pemerintah). Pengaruh yang dimaksud adalah terkait modelmultipleksing yang seharusnya digunakan. ATVSI dengan hybrid multipleksing dan ATVNI bersama ATVLI dengan single multipleksing.

Model single multipleksingadalah model dimana hanya ada satu penyelenggara layanan multipleksing penyiaran digital, dalam hal ini pemerintah melalui LPP. LPS menyewa kanal frekuensi untuk melakukan kegiatan penyiarannya. Pemikiran dasar teoritis single multipleksing yang bisa digunakan adalah Golding-Murdock juga menggarisbawahi bahwa pemerintah harus berdiri dan berada di posisi paling puncak dengan kekuatan regulasinya

Tabel 2. Perbandingan Beberapa RUU tentang Penyiaran Digital

\begin{tabular}{|c|c|c|c|c|c|}
\hline No & Regulasi & $\begin{array}{l}\text { Lembaga } \\
\text { Penyiaran }\end{array}$ & $\begin{array}{c}\text { Sistem } \\
\text { multipleksing }\end{array}$ & Penyelenggara & $\begin{array}{l}\text { Pembagian kanal } \\
\text { frekuensi }\end{array}$ \\
\hline \multirow[t]{2}{*}{1} & \multirow{2}{*}{$\begin{array}{l}\text { Draft RUU } \\
\text { Februari } \\
2016\end{array}$} & $\begin{array}{l}\text { LPP, LPS, } \\
\text { LPK, LPB }\end{array}$ & Multi & $\begin{array}{l}\text { LPP, LPS dan LPK } \\
\text { yang memiliki IPP }\end{array}$ & $\begin{array}{l}\text { LPP, LPS dan LPK } \\
\text { yang memiliki IPP, } \\
\text { satu kanal frekuensi }\end{array}$ \\
\hline & & $\begin{array}{l}\text { Pasal } 1 \text { ayat } \\
9-13\end{array}$ & Pasal 23 dan 24 & Pasal 24 ayat 1 & Pasal 24 ayat 1 \\
\hline \multirow[t]{2}{*}{2} & \multirow{2}{*}{$\begin{array}{l}\text { Draft RUU } \\
\text { Maret } \\
2017\end{array}$} & $\begin{array}{l}\text { LPP, LPS, } \\
\text { LPK, LPB, } \\
\text { LPPM }\end{array}$ & Hybrid & $\begin{array}{l}\text { LPPM yang memiliki } \\
\text { IPM }\end{array}$ & $\begin{array}{l}\text { Satu LPPM, satu } \\
\text { kanal frekuensi }\end{array}$ \\
\hline & & $\begin{array}{l}\text { Pasal } 1 \text { ayat } \\
11-15\end{array}$ & Pasal 83 & Pasal 83 ayat 3 & $\begin{array}{l}\text { Penjelasan Pasal } 83 \\
\text { ayat } 2\end{array}$ \\
\hline \multirow{2}{*}{3} & \multirow{2}{*}{$\begin{array}{l}\text { Draft RUU } \\
\text { Oktober } \\
2017\end{array}$} & $\begin{array}{l}\text { LPP, LPS, } \\
\text { LPK, LPB, } \\
\text { LPKhusus }\end{array}$ & Single & LPP TVRI & $\begin{array}{l}\text { LPP, dan LPS yang } \\
\text { memilik IPP, satu } \\
\text { kanal frekuensi }\end{array}$ \\
\hline & & $\begin{array}{l}\text { Pasal } 1 \text { ayat } \\
10-15\end{array}$ & Pasal 20 ayat 1 & Pasal 20 ayat 3 & Pasal 20 ayat 3 \\
\hline
\end{tabular}

Sumber: Dokumen Peneliti, (2017) 
untuk mengatur semua elemen sosial dalam komunikasi demi mewujudkan keseimbangan dan keteraturan antara kepentingan publik dan kepentingan komersial (konsep public sphere Habermass). Pemerintah tidak hanya sebagai regulator dari para perusahaan media, tetapi juga sebagai sebuah institusi komunikator yang mempunyai kekuatan yang sangat besar (lihat Curran dan Gurevitch, 1991:24-25). Selain itu, dalam mukadimah UU No. 32/2002 tentang Penyiaran menuliskan bahwa frekuensi merupakan sumber daya alam terbatas dan kekayaan nasional yang harus dijaga dan dilindungi oleh negara dan dipergunakan untuk sebesar-besarnya kemakmuran rakyat. Melihat dasar pemikiran tersebut, frekuensi seharusnya dikuasai oleh negara dan pengelolaannya dilakukan oleh negara, dalam hal ini pemerintah. Single multipleksing merupakan model penyiaran digital yang paling tepat digunakan sebagai dasar sistem penyiaran digital di Indonesia, dimana semua LPS baik yang besar, kecil maupun lokal akan menyewa kanal frekuensi kepada pemerintah. Segala regulasi terkait penggunaan dan penyewaan kanal frekuensi juga akan ditentukan oleh pemerintah. Dilihat dari sisi ekonomi, dengan tidak adanya penguasaan kanal frekuensi oleh LPS, tidak akan terjadi oligopoli bisnis penyiaran televisi digital dan akan menjadikan persaingan bisnis yang adil. Tentunya modelsingle multipleksing akan lebih dekat dengan asas open access, equal opportunity dan fair price sehingga lebih memihak kepada kepentingan publik dibandingkan dengan sistem hybrid atau multimultipleksing.

Pemerintah sebenarnya sudah mempunyai kecenderungan pendirian terhadap single multipleksing. Hal tersebut dapat dilihat pada RUU terbaru versi Oktober 2017. Dan untuk menegaskan kembali, baru-baru ini berdasarkan hasil Forum Koordinasi dan Konsultasi (FKK) tentang Migrasi Televisi Analog ke Televisi Digital yang diselenggarakan pada 8 Maret 2018, Menkopolhukam memberikan maklumat yang berisi himbauan pemercepatan proses penyelesaian Revisi UU Penyiaran dan mendukung penggunaan model single multipleksing. Maklumat tersebut menunjukkan bahwa pemerintah sebagai struktur berusaha memperlihatkan pengaruhnya yang lebih besar terhadap agen. Varian kajian ekonomi politik kritis ini dinamakan Strukturalisme, yang cenderung melihat struktur sebagai totalitas yang solid dan permanen. Struktur dianggap memiliki superioritas terhadap agen.

InterplayAgen-Struktur: Win-Win Solution RUU Penyiaran Versi Oktober 2017

Sistem single multipleksing memang mengalami penolakan oleh beberapa LPS, terutama oleh LPS yang tergabung dalam ATVSI. Salah satu faktor yang memberatkan penggunaan sistem single multipleksing adalah mubazirnya infrastruktur yang telah diinvestasikan. Kembali ke tahun 2012, ketika Kemkominfo mengeluarkan hasil seleksi LPS untuk mejadi LPPM, LPS-LPS terpilih sudah menginvestasikan dananya yang tidak sedikit dalam bentuk infrastruktur dalam rangka menunjang dirinya menjadi LPPM. Tentu LPS-LPS ini berharap multi atau hybrid multipleksing lah yang terpilih agar investasi yang telah mereka keluarkan tidak mubazir.

Pada April 2016, untuk pengkajian lebih mendalam lagi, Kemkominfo kembali mengeluarkan Permen Kominfo No. 5/2016 tentang Uji Coba Teknologi Telekomunikasi dalam rangka penelitian dan penetapan arah kebijakan penyelenggaraan penyiaran digital. Permen ini men-trigger munculnya stasiun televisi-stasiun televisi digital baru di Indonesia, baik yang tadinya sudah melakukan siaran teresterial secara analog maupun yang benarbenar pemain baru di penyiaran teresterial. Mereka berani berspekulasi menginvestasikan dananya yang tentunya tidak sedikit dalam membangun infrastruktur, bahkan sekarang sudah berdiri aliansinya yaitu Asosiasi Televisi Siaran Digital Indonesia (ATSDI). 
ATSDI yang beranggotakan sebanyak 65 stasiun televisi digital tentu muncul sebagai agen baru dalam pembuatan norma penyiaran digital di Indonesia. Berbeda dengan ATVSI, ATSDI bergabung bersama ATVNI dan ATVLI sebagai agen yang mendukung penggunaan single multipleksing. Ini menjadi sesuatau yang menarik, karena di satu sisi, ATSDI mendukung single multipleksing, yang mana nantinya penyelenggaraan multipleksing ada di tangan pemerintah, di sisi lain ATSDI sudah menginvestasikan infrastruktur, yang tentunya juga tidak ingin investasinya mubazir atau sia-sia begitu saja.Kemungkinan mubazirnya infrastruktur penyiaran digital beberapa stasiun televisi menjadi permasalahan yang serius bagi pemerintah sebagai struktur dalam menentukan kebijakan.

Konsep strukturasi Giddens digunakan oleh Golding-Murdock ketika melihat adanya interplay, interaksi timbal balik antara struktur dan agen, pengaruh yang sama kuatnya antara struktur dan agen yang pada akhirnya menghasilkan sebuah norma yang saling mengutungkan (win-win solution).Keadaan ini dinamakan juga dengan Konstruktivisme oleh Golding-Murdock (Sudibyo, 2004:3).

Seperti yang dapat dilihat pada Tabel 2,RUU Penyiaran tertanggal Oktober 2017 memilih single multipleksing sebagai model penyiaran digital, akan tetapi RUU ini juga memperlihatkan hasil adanya interplay antara agen dan struktur melihat permasalahan secara dua sisi antara model multipleksing yang digunakan dan mubazirnya infrastruktur yang sudah terlanjur dibangun. Pada Pasal 20 ayat 3 menyatakan: "Dalam rangka melaksanakan migrasi Penyiaran analog ke digital sebagaimana dimaksud dalam Pasal 20 ayat (1), LPP berwenang: a) mengelola dan memanfaatkan frekuensi Penyiaran dengan teknologi digital yang dimilikinya; dan b) bertindak sebagai pelaksana penyedia infrastruktur Penyiaran digital di setiap Wilayah Siar.”
Ayat 4 menyatakan:

"LPP dalam menjalankan kewenangannya sebagaimana dimaksud pada ayat (3) huruf b, wajib menyediakan infrastruktur Penyiaran digital dan/atau mengakuisisi infrastruktur Penyiaran Lembaga Penyiaran yang telah memiliki IPP di seluruh Wilayah Siar."

Dari kedua ayat di atas, jelas menjawab akan keresahan LPS yang sudah menginvestasikan dalam bentuk infrastruktur, karena negara akan mengakuisisinya dan akan digunakan untuk menyelenggarakan penyiaran digital di Indonesia. Terkait bentuk teknis akuisisi akan diatur lebih lanjut dalam tataran aturan yang lebih teknis nantinya. Yang pasti, infrastruktur LPS yang sudah terbangun tidak akan mubazir. Norma ini merupakan hasil dari interplay agen dan struktur yang saling memberikan pengaruhnya sama kuat dan membuahkan hasil yang win-win solution.

\section{Regulasi Penyiaran Indonesia ke Depannya: Sebuah Gagasan}

Shoemaker-Reese (1996) membagi media menjadi dua berdasarkan isi konten di dalamnya. Market approach, adalah media yang berisi konten dengan pendekatan pasar, dengan memberikan apa yang dimau oleh penonton, sehingga mendatangkan banyak penonton dan dengan tujuan akhir yaitu keuntungan yang berasal dari para pengiklan. Media jenis ini adalah para LPS. Social responsibility approach, adalah media yang secara konten lebih memberikan apa yang dibutuhkan penonton, daripada apa yang diinginkan penonton. Media jenis ini adalah LPP (Shoemaker-Reese, 1996:7).

Secara kuantitas, perbandingan LPP dan LPS di Indonesia jelas tidak berimbang. Dominasi LPS menyebabkan konten atau program siaran televisi yang beredar di sebuah wilayah siar, yang mana itu adalah ranah publik (public sphere), didominasi oleh program komersial berupa program hiburan. Dari data yang dihimpun, berdasarkan jadwal program acara harian beberapa LPS, perbandingan antara program hiburan dengan program informasi dalam jadwal siar satu hari 
Tabel 3. Perbandingan Program Siaran Beberapa Lembaga Penyiaran

\begin{tabular}{ccc}
\cline { 2 - 3 } Lembaga Penyiaran & Hiburan & Informasi \\
\cline { 2 - 4 } Indosiar & $73 \%$ & $27 \%$ \\
ANTV & $87 \%$ & $13 \%$ \\
SCTV & $73 \%$ & $27 \%$ \\
TransTV & $70 \%$ & $30 \%$ \\
RCTI & $86 \%$ & $14 \%$ \\
RTV & $76 \%$ & $24 \%$ \\
\hline
\end{tabular}

Sumber: www.jadwaltv.net, (2017)

terlihat pada tabel 3 yang menunjukkan bahwa program hiburan mendominasi program acara di sebuah lembaga penyiaran yang bisa mengakibatkan terjadinya homogenitas konten, yaitu konten hiburan, yang akan semakin menjauhkan dari terwujudnya kualitas masyarakat yang berwawasan luas.

Teknologi penyiaran digital yang memungkinkan menghadirkan banyak saluran televisi di sebuah wilayah siar menjadi pintu masuk regulasi penyiaran untuk mengatur kesimbangan konten atau program siaran yang beredar. Golding-Murdock memandang public sphere sebagai ruang yang menyajikan keseimbangan informasi dalam hal ini konten atau program siaran, keseimbangan antara kepentingan pihak tertentu (privat atau swasta) dan kepentingan publik. Dan untuk mencapai kondisi komunikasi ideal tersebut dibutuhkannya peran sentral pemerintah dengan cara pemberdayaan agen pemerintah sebagai alat kontrol dan pemenuhan kebutuhan informasi untuk publik (Curran dan Gurevitch, 1991:24).

Berdasarkan paparan di atas, menimbang konsep Golding-Murdock terkait pemenuhan kebutuhan informasi untuk publik dan melihat keunggulan teknologi penyiaran digital yang bisa menghadirkan banyak saluran televisi dalam sebuah wilayah siar, perlu didirikannya lagi sejumlah Lembaga Penyiaran Publik (LPP) yang tentunya akan memberikan lebih banyak informasi tentang berbagai aspek kehidupan kepada masyarakat. Misalnya di sektor pendidikan disiarkannya TV Edukasi, berada di bawah naungan Kemdikbud yang berisi tentang konten-konten pembelajaran siswa-siswa; Di sektor politik, disiarkannya KPUTV, berada di bawah naungan Komisi Pemilihan Umum (KPU) yang berisi informasi politik di Indonesia. Dimana KPUTV ini akan menjadi satu-satunya lembaga penyiaran yang boleh menyiarkan program siaran yang berisi atau bermuatan politik dari partaipartai politik. Jadwal penayangan menjadi wewenang penuh dari pengelola yaitu KPU, dan akan dibuat seadil-adilnya dimana setiap partai akan mendapatkan hak yang sama dalam menyiarkan program siarannya; Di sektor ekonomi disiarkannya OJKTV, berada di bawah naungan Otoritas Jasa Keuangan (OJK) yang berisi informasi mengenai jasa keuangan di Indonesia, informasi investasi keuangan yang aman untuk masyarakat Indonesia; Dan tentunya masih banyak lagi LPP yang bisa dikembangkan berdasarkan aspek kehidupan masyarakat.

Kehadiran LPP-LPP ini tentunya akan mengubah komposisi LPP-LPS menjadi lebih seimbang. Pada akhirnya juga akan menambah ragam konten atau program acara yang beredar di ranah publik. LPP dengan muatan konten yang lebih banyak mengedepankan apa yang dibutuhkan penonton tentunya akan lebih banyak berisi informasi-informasi untuk mencerdaskan kehidupan bangsa. 


\section{Simpulan}

Kehadiran regulasi digitalisasi penyiaran sangat dinantikan semua elemen penyiaran di Indonesia. Regulasi ini merupakan pintu masuk masa depan penyiaran Indonesia. Lamanya proses pembahasan regulasi ini tak luput dari pengaruh dinamika ekonomi politik yang ada di belakangnya. Pengaruh agen, yaitu para lembaga penyiaran, sangatlah besar dan membuat negara atau pemerintah sebagai struktur tidak bisa semudah membalikkan telapak tangan dalam membuat norma/aturan yang mengatur keberlangsungan ekosistem sosial yang terbentuk. Hal ini menunjukkan adanya proses saling pengaruh antara struktur dan agen, proses ini oleh Giddens disebut dengan strukturasi. Dalam perjalanan waktu pembuatan regulasi digitalisasi penyiaran ini, menurut pandangan ekonomi politik kritis terjadi varian instrumentalisme, strukturalisme maupun konstruktivisme dengan interplaynya.

Berdasarkan hasil penelitian ini dapat disimpulkan bahwa penggunaan pertimbangan terciptanya ranah publik (public sphere) yang berisi keseimbangan antara kepentingan privat dan kepentingan publik, dan juga tidak terciptanya oligopoli bisnis dalam penyiaran Indonesia, single multipleksing merupakan model yang paling ideal untuk penyiaran digital di Indonesia, dimana frekuensi dikuasai oleh negara dan pengelolaannya dilakukan oleh negara, dalam hal ini pemerintah. Harus tercipta juga interplay antara agen dan struktur agar tercipta norma/aturan dengan dasar winwin solutionuntuk menjaga keberlangsungan agen dan struktur dalam menjalankan perannya masing-masing dalam penyiaran di Indonesia.

Penelitian ini memberikan rekomendasi berupa kebijakan bahwa ekonomi politik seharusnya diletakkan untuk melindungi kepentingan publik. Regulasi penyiaran digital yang nantinya terbentuk haruslah didasari keseimbangan antara kepentingan privat dan kepentingan publik, yaitu dengan seimbangnya konten/programsiaranyangberedar, antarakonten dengan pendekatan pasar (market approach) dan konten dengan pendekatan tanggung jawab sosial (social responsibility approach). Tentunya inilah esensi yang sesungguhnya dari penyiaran dengan diversity of ownership dan diversity of content.

\section{Daftar Pustaka}

Ashrianto, Panji Dwi. (2015). Studi Kesiapan Lembaga Penyiaran Terhadap Penerapam Sistem Penyiaran Berteknologi Digital di Yogyakarta. Jurnal Ilmu Komunikasi, 13(2), 158-172. Adnjani, Made Dwi dan Mubarok. (2018). Strategi Sosialisasi Migrasi Sistem Penyiaran Analog Ke Digital Di Jawa Tengah. Jurnal ASPIKOM, 3(4), 755-766. Budiman, Ahmad. (2015). Model Pengelolaan Digitalisasi Penyiaran di Indonesia. Jurnal Politica, 6(2), 107-122. Djamal, Hidajanto dan Fachuddin, Andi. (2011). Dasar-Dasar Penyiaran Sejarah Organisasi Operasional dan Regulasi. Jakarta: Kencana Eadie, William F. (2009). 21 $1^{\text {st }}$ Century Communication: A reference handbook. London: Sage Publication, Inc. Golding, Peter \& Graham Murdock. (1991). "Culture, Communications and Political Economy". James Curran and Michael Gurevitch (Eds.). Mass Media and Society. London: Edward Arnold: hal. 15-32 McQuail, Denis (2010). Mass Communication Theory. London: Sage Mosco,Vincent. (2009). The Political Economy of Communication. 2nd ed. London: Sage Publications. Peraturan Menteri. (2011). Peraturan Menteri (Permen) Kominfo No. 22 tahun 2011 tentang Penyelenggaraan Digitalisasi Penyiaran. Sekretariat Negara. Jakarta. Peraturan Menteri. (2011). Peraturan Menteri (Permen) Kominfo No. 23 tahun 2011 tentang Rencana Induk 
(Masterplan) Frekuensi Radio. Prabowo, Agung dan Arofah, Kurnia. (2017).

Media Sosial Instagram Sebagai Sarana

Sosialisasi Kebijakan Penyiaran Digital. Jurnal ASPIKOM, 3(2), 256-269. Prabowo, Agung. (2012). Era Penyiaran Digital: Pengembangan atau Pemberangusan TV Lokal dan TV Komunitas?. Jurnal Komunikasi, 1(4), 301-314. Republik Indonesia. (2002). Undang Undang No 32 tahun 2002 tentang Penyiaran. Lembaran Negara RI Tahun 2002. Sekretariat Negara. Jakarta.
Sitepu, Mehulika. (2018). Menjamurnya situs berita: Bagaimana Agar Media Digital Dapat Bertahan?http://www. bbc.com/indonesia/majalah-42659511 Sudibyo, Agus. (2004). Ekonomi Politik Media Penyiaran. Yogyakarta: LKiS Wasko, Janet. (2004). "The Political Economy of Communications". Dalam John D.H.Downing, Denis McQuail, Philip Schlesinger, \& Ellen Wartella (Eds.), The Sage Handbook of Media Studies. Thousand Oaks: Sage Publications: hal. 309-330. 